\title{
Saint-Romain-en-Gal - Église paroissiale
}

\section{Benoît Helly}

URL : http://journals.openedition.org/adlfi/15480

ISSN : 2114-0502

Éditeur

Ministère de la culture

\section{Référence électronique}

Benoît Helly, "Saint-Romain-en-Gal - Église paroissiale », ADLFI. Archéologie de la France - Informations [En ligne], Rhône-Alpes, mis en ligne le 26 août 2015, consulté le 01 mai 2019. URL : http:// journals.openedition.org/adlfi/15480

Ce document a été généré automatiquement le 1 mai 2019.

(c) Ministère de la Culture et de la Communication, CNRS 


\title{
Saint-Romain-en-Gal - Église paroissiale
}

\author{
Benoît Helly
}

Code INSEE de la commune : 69235

Lien Atlas (MCC) :

http://atlas.patrimoines.culture.fr/atlas/trunk/index.php?

ap_theme=DOM_2.01.02\&ap_bbox=4.789;45.521;4.873;45.559

1 Conservée intégralement en plan et en élévation, l'église paroissiale de Saint-Romain-enGal mérite une étude scientifique, commencée par J.-F. Reynaud dans les années 1970 (plan et relevé des élévations sud et nord) mais non achevée en particulier faute de datation précise. L'étude a repris ces dernières années avec des prélèvements par les laboratoires de thermoluminescence de Bordeaux (P. Guibert) et d'archéomagnétisme de Rennes (Ph. Lanos) qui commencent à fournir des datations provisoires (entre 450 et 650 pour la thermoluminescence). Une relecture des textes (Passions et vies de Ferréol, Grégoire de Tours) concernant le martyrium de Ferréol, nous a poussé à émettre l'hypothèse que l'église de Saint-Romain-en-Gal était l'église reconstruite par l'évêque de Vienne Mamert, à l'abri des inondations sur la terrasse dominant la plaine d'une vingtaine de mètres, et donc peu après 473.

Le but de la recherche de terrain était donc d'abord d'obtenir une couverture complète de l'élévation de l'édifice. Les relevés anciens ont été numérisés par Benoît Helly et complétés par des photos laser effectuées par A. Flammin (CNRS, UMR5138).

Le but était également de savoir si un «sol» de dalles liées par un mortier de tuileau repéré dans la cave à l'ouest de l'église pouvait être mis en rapport avec le sol ancien de l'église. Nous avons donc nettoyé les murs nord, sud et ouest de la cave qui correspondent à l'extrémité occidentale de l'église (le mur est ayant été installé lors de l'implantation de la cave). Il nous est rapidement apparu que le «sol» de dalles liées par un mortier de tuileau au sud de la cave était en fait une structure conservée en fondations qui s'appuyait sur le mur occidental de l'église et que l'on avait l'équivalent au nord: 
structures conservées en fondation de 1,50 à $2 \mathrm{~m}$ d'épaisseur et comportant de grosses dalles. On a pu vérifier également la présence de deux sarcophages en place dans le mur est de la cave : l'un dont la cuve rectangulaire a été en partie conservée en saillie à l'intérieur de la cave, l'autre dont la cuve est en partie détruite mais dont le couvercle est encore en place. Un troisième sarcophage rectangulaire aux parois épaisses est déposé en façade occidentale de l'édifice.

4 Nous avons également procédé à un nivellement général du site qui suggère que le seuil de la porte sud devait être à environ 20 à $30 \mathrm{~cm}$ sous le niveau actuel, et donc que le sol de l'église a été quelque peu abaissé.

5 Nous devons donc expliquer la présence de deux structures puissantes installées à l'ouest de l'église postérieurement à la construction et conservées en élévation sur quelques dizaines de centimètres. On pourrait estimer, mais sans preuve, qu'elles ont été installées peu après la construction du gros œuvre, et supposer un arc monumental destiné à abriter une tombe, du genre de celui de l'église funéraire de Sainte-Quitterie à Aire-surAdour. En effet, Grégoire de Tours (Virt.S.Juliani) en visite sur la tombe de Saint-Ferréol lève la tête pour lire un texte écrit sur le tribunal. Le terme de jubé conviendrait mal et nous avons adopté la traduction de tribune en accord avec G. Lucas. Nous suggérons donc qu'il s'agit d'une sorte d'arcosolium monumental au-dessus de la tombe du saint, transférée des rives du Rhône à la colline.

\section{INDEX}

Index chronologique : Antiquité tardive, haut Moyen Âge

Mots-clés : fondations, sarcophage, église, arcosolium

Index géographique : Rhône-Alpes, Rhône (69), Saint-Romain-en-Gal

Keywords : Late Antiquity, Early Middle Ages

operation Sondage (SD)

\section{AUTEURS}

\section{BENOÎT HELLY}

SRA 